\title{
Nuevos recursos para el uso de la literatura en lengua inglesa en Educación Infantil y Primaria
}

\author{
Patricia JIMÉNEZ VILLACORTA \\ patricia.jimenez.villacorta@gmail.com
}

Recibido: 10 de marzo de 2016

Aceptado: 29 de septiembre de 2016

\section{RESUMEN}

La literatura en el aprendizaje de lenguas extranjeras es un elemento importante para aportar a los alumnos no sólo un contexto lingüístico, sino también sociocultural. Además, si se escoge bien, es una fuente de placer y entretenimiento, que puede conseguir que los alumnos se motiven y tengan una predisposición más positiva hacia ese idioma, lo cual influye finalmente en una mejora del aprendizaje. Actualmente, las nuevas tecnologías e Internet permiten acercar la literatura a las aulas de una manera más fácil. El objetivo principal de este artículo consiste en la presentación de una serie de nuevos recursos para mejorar la utilización de la literatura en inglés en los centros de Educación Infantil y Primaria.

Palabras clave: Literatura infantil, aprendizaje del inglés, tecnologías de la información y la comunicación (TIC), biblioteca escolar.

New resources for using literature in English in Infant and Primary Education

\begin{abstract}
While learning foreign languages, literature is an important element, providing our pupils not only linguistic but also socio-cultural context. Therefore, if well chosen, it is a source of pleasure and entertainment, fostering motivation and a more positive predisposition to that language, which can lead to an improvement in learning. Nowadays, the new technologies and the Internet can bring literature closer to schools, more easily. The main aim of this article is to present a series of different resources to improve the utilization of literature in English in Infant and Primary Schools.

Key words: Children literature, English learning, information and communication technologies (ICT), school library.

Des nouveaux ressources pour utiliser la littérature en langue Anglaise dans

RÉSUMÉ l'École Maternelle et Élémentaire

Dans l'apprentissage des langues étrangeres, la littérature est un élément important pour donner un contexte socioculturel aux élèves. En outre, si on fait un bon choix, elle est une source de plaisir et amusement, ce qui produit une augmentation de la motivation et une prédisposition plus possitive des élèves, et qui a de l'influence en leur apprentissage.
\end{abstract}


Aujourd'hui, les nouveaux technologies et l'Internet permettent de rapprocher la littérature aux écoles d'une façon plus facile. L'objective principal de cet article est présenter un ensemble de ressources pour amélorier l'usage de la littérature en anglais dans les Écoles Maternelles et Élémentaires.

Mots-clés: Littérature pour enfants, apprentissage de l'anglais, technologies de l'information et de la communication (TIC), bibliothèque scolaire.

SUMARIO: 1. Introducción: la literatura, elemento clave; 2. Recursos para el uso de textos literarios en inglés en centros de Educación Infantil y Primaria; 2.1. ¿Cómo seleccionar los textos?; 2.2. ¿Dónde encontrar literatura en lengua inglesa adecuada a los alumnos de Infantil y Primaria?; 2.3. Storytelling; 2.4. Obras de teatro; 2.5. Cómics; 2.6. Nursery Rhymes y poesía; 2.7. La biblioteca escolar; 2.8. El portfolio literario del profesor; 2.9. Recursos adicionales. Páginas web y libros recomendados; 3. Conclusión; 4. Bibliografía.

\section{INTRODUCCIÓN: LA LITERATURA, ELEMENTO CLAVE}

La literatura, desde hace siglos, cumple una serie de funciones muy importantes en la sociedad. Puede servir para la transmisión de valores y conocimiento; como una fuente de placer y entretenimiento; como ayuda para el desarrollo de la personalidad individual y colectiva; y también como apoyo importante para el aprendizaje de idiomas. La literatura en la escuela puede ser un elemento clave para desarrollar las cuatro habilidades básicas (listening, speaking, reading, writing), ya que:

- La literatura, utilizada de formas variadas, puede ser muy motivadora, tanto para los alumnos como para el profesor.

- Aportar textos literarios en lenguas extranjeras a las aulas facilita el acceso a contenidos variados y en contexto para todos los alumnos, fácilmente adaptable a las necesidades y el nivel de cada uno.

- El uso de la literatura puede dar pie a utilizar otros recursos metodológicos variados y disponibles a nuestro alcance.

Con las nuevas tecnologías e internet, tenemos a nuestra disposición una serie de nuevos recursos que nos pueden ayudar a ampliar y mejorar el uso de la literatura en nuestras escuelas.

\section{RECURSOS PARA EL USO DE TEXTOS LITERARIOS EN INGLÉS EN LAS AULAS DE EDUCACIÓN INFANTIL Y PRIMARIA}

\section{1. ¿Cómo seleccionar los textos?}

Ellis y Brewster (1991, 9-10) recomiendan principalmente libros con textos literarios auténticos ${ }^{1}$, ya que aportan ejemplos de lenguaje nativo y ayudan a acercar

\footnotetext{
${ }^{1}$ Se consideran textos literarios auténticos aquellos que han sido escritos por hablantes nativos de ese idioma, y que han sido publicados en contextos diseñados específicamente para el
} 
el mundo real al aula. Estos libros pueden ser además muy motivadores para los alumnos, ya que con ellos experimentan un fuerte sentimiento de logro. Por último, hay que señalar que la edición y las ilustraciones de estos libros, sobre todo las de los álbumes ilustrados, suelen ser más atractivas y de mayor calidad que los libros pedagógicos y/o adaptados al MCER (conocidos como graded readers).

Existen muchas clases distintas de libros para niños. Dependiendo de lo que se quiera, se necesite y les guste a nuestros alumnos, se pueden elegir entre una gran variedad: historias tradicionales y cuentos de hadas, conocidos por los alumnos en su propia L1; historias con solo imágenes, donde los alumnos pueden construir la historia juntos; cuentos rimados; historias acumulativas con finales predecibles (o no); historias humorísticas, cotidianas, fantásticas y de animales; libros con pop-ups o lift the flaps; etc. La dificultad lingüística es un factor que también hay que tener en cuenta. Es mejor seleccionar una obra que esté un poco por encima de la capacidad lectora actual de los estudiantes: no muy fáciles, pues serían poco estimulantes o muy aburridos; no muy difíciles, ya que generarían frustración en los alumnos.

El British Council (2006) sugiere unos criterios de selección de libros enfocados al aprendizaje del inglés, graduado por niveles y teniendo en cuenta ambos factores:

- Infantil. Textos atractivos, repetitivos o que rimen, que se puedan leer en voz alta, que permitan la participación de los niños a través de frases pegadizas, a través de historias simples que los niños puedan repetir y representar y por medio de canciones o chants.

- Primero y segundo de Primaria. Textos que exijan a los alumnos desarrollar su conocimiento fonológico, búsqueda de vocabulario y habilidades de decodificación; que presenten características del lenguaje y técnicas usadas para conseguir un determinado efecto (humor, repetición, rima); que incluyan palabras, ideas y dibujos que ayuden a los niños a empezar a comprender a los personajes y los sucesos, y cómo los describen los autores; que atraigan su interés y estén relacionados con experiencias familiares e imaginarias, en distintos mundos y culturas; textos tanto clásicos como nuevos, escritos con diferentes estilos y técnicas; textos con un tamaño de letra grande y legible.

- Tercero y cuarto de Primaria. Textos que exijan a los alumnos desarrollar su vocabulario y su habilidad para leer frases un poco más complejas, como por ejemplo con lenguaje figurado; que requieran una lectura un poco más prolongada; que muestren cómo los autores retratan a sus personajes, establecen la trama a través del diálogo, la acción y la interacción; que incluyan historias clásicas y tradicionales y poemas, así como algunos que incluyan

consumo de hablantes nativos en esa lengua, sin consideración a la accesibilidad para los no-nativos. Disponible en la web: http://www.cambridge.org/elt/blog/2014/05/authenticmaterials-classroom-advantages/ [Consulta: 23/09/2016]. 
temas un poco más exigentes; que les pidan una respuesta lectora más profunda (por ejemplo, habilidades de inferencia y deducción); que representen una variedad de técnicas y estilos, y de otras culturas.

- Quinto y sexto de Primaria. Textos que exijan a los niños un mayor entendimiento de cómo se desarrollan los personajes y las tramas a lo largo del libro; que aporten una variedad de géneros (ciencia ficción, ficción histórica, mitología, textos clásicos, historias contemporáneas y poemas) y una variedad de autores, tanto clásicos como actuales; que requieran mayor tiempo de lectura; que sirvan de ejemplo de estructuras más complejas, a veces incluso situados en diferentes tiempos, mundos y culturas; que sean atractivos tanto por su contenido como por su estilo.

\section{2. ¿Dónde encontrar literatura en lengua inglesa adecuada a los alumnos de Infantil y Primaria?}

Actualmente, con las nuevas tecnologías y las tiendas por Internet encontrar literatura en distintos idiomas es más fácil. Algunas librerías online, por ejemplo, ofrecen una gran variedad de títulos, algunos de ellos en versión e-book, que además de ser más económicos, permiten su proyección con un proyector o con una pizarra digital. Muchas de estas librerías tienen una vista previa que nos permite ver las ilustraciones y los textos y valorar si son adecuados o no para nuestros propósitos. Existen multitud en la red, y son muy fáciles de encontrar. Sin embargo, es interesante la cantidad de recursos online gratuitos disponibles, como por ejemplo:

- British Council Kids - Sitio para niños del British Council. Tiene cuentos tradicionales, tonguetwisters y nursery rhymes, mezclados con otras rimas y cuentos específicos para aprender inglés, que se pueden usar en clase, entre otros recursos. Se puede ver en: http://learnenglishkids.britishcouncil.org/en/. Para un poco más de nivel encontramos en esta misma página -más en concreto en $\mathrm{http} / / /$ learnenglish.britishcouncil.org/en/stories-poems y en http:// learnenglishteens.britishcouncil.org/uk-now/stories-and-poems-uk- historias, poemas y actividades relacionadas, algunas con audio incluido; y otras más, graduadas por niveles del MCER (A2, B1 y B2) en http://learnenglishteens. britishcouncil.org/study-break/easy-reading.

- BritLit - https://www.teachingenglish.org.uk/britlit. Sitio también del British Council de actividades basadas en literatura, preparadas para utilizar en el aula. Los textos suelen incluir flashcards y otros materiales descargables. Aunque la sección de Primaria es breve, para alumnos de tercer ciclo se puede utilizar la de Young Teens.

- Promoting diversity through children's literature - Sección de actividades y fichas de trabajo muy completas, creadas por el British Council Centre de París, y relacionadas con 6 libros ilustrados para niños que los profesores de este centro utilizaron en un programa desarrollado en verano de 2010. Las 
actividades se encuentran en: https://www.teachingenglish.org.uk/category/ tags/promoting-diversity-through-children's-literature. Requiere registro (gratuito).

- BBC Schools - En http://www.bbc.co.uk/education/topics/zd66fg8. Pequeños vídeos muy interesantes de obras cortas - poemas, cuentos, nursery rhymes- por niveles (en Primary: KS1, Early and 1st level, KS2, 2nd level, ver en la sección de English / Reading literary and fiction texts). También da ideas sobre posibles actividades para hacer en clase.

- Readwritethink - Interesante sitio web de la International Reading Association (http://www.readwritethink.org/) en colaboración con el National Council of Teachers of English (NCTE, USA), dedicado exclusivamente al asesoramiento de educadores, padres y profesores de clases extraescolares, mediante la publicación de materiales gratuitos de lectoescritura y arte literario para su uso en clase. Tienen una gran variedad de materiales graduados por edades.

- DLTK's Crafts for Kids - Cientos de actividades y manualidades para niños relacionadas con cuentos tradicionales, cuentos mitológicos y nursery rhymes: http://www.dltk-teach.com/rhymes/index.htm.

- The Story Museum. 1001 stories - Historias de todo tipo, de todas partes del mundo, clasificadas por edades, temática y el origen de la historia. Muchas con audio y actividades para hacer. En: http://www.storymuseum.org.uk/ 1001stories/

- Gutenberg Project - www.gutenberg.org. La mayor colección de libros electrónicos gratuitos, en distintos formatos (epub, pdf, html, plucker, kindle, etc.).

- Folklore and Mythology (Electronic Texts), editado por la Universidad de Pittsburg. Disponible en http://www.pitt.edu/ dash/folktexts.html . Se trata de un compendio vastísimo de literatura popular de distintas partes del mundo, clasificados por temas.

- Stories to Grow By with Whootie Owl (http://www.storiestogrowby.com/ choose.html) - La sección Choose a Story de la página de Whootie Owl tiene un buscador de cuentos en el que se pueden encontrar historias adaptadas por edad o por temática.

- En el blog Brain Pickings se pueden encontrar algunos textos interesantes, como por ejemplo, una muestra de poemas de la recopilación ilustrada Beastly Boys and Ghastly Girls, poemas irreverentes para niños (http://www.brain pickings.org/index.php/2013/03/19/beastly-boys-and-ghastly-girls-coleungerer-1964/).

- Lit2Go - Colección gratuita de novelas, cuentos y poemas desarrollado por la University of Southern Florida, que se pueden escuchar y leer online, y también descargar e imprimir (http://etc.usf.edu/lit2go/authors/). 
- Classic Reader. Cientos de libros gratuitos de autores como Dickens, Austen, Shakespeare y otros muchos (http://www.classicreader.com/).

- Pinterest. Página web con multitud de imágenes que también tiene ilustraciones de cuentos y fichas de actividades para hacer con ellos. Requiere registro y buscar específicamente el cuento que se quiere trabajar. www.pinterest.com.

A lo largo del artículo se incluyen más, específicas por género.

\subsection{Storytelling}

Una de las actividades que se hacen más a menudo con los alumnos de Educación Infantil y, sobre todo, en los primeros años de Primaria, es la de contar cuentos. Sin embargo, contar cuentos bien es difícil, requiere cierta práctica y conocer técnicas orales y visuales. Ellis (2013) considera que para usar los libros ilustrados de manera efectiva es necesario planificarlo previamente de una manera clara y concisa. Para ello establece una serie de estrategias:

- Usar la portada, haciendo preguntas y despertando la curiosidad de los alumnos.

- Usar la página del título interior, de nuevo haciendo preguntas.

- Preparar a los niños lingüísticamente y conceptualmente antes de leer/contar la historia en voz alta con diversas actividades o con un mapa conceptual simple. Pueden usar su lengua materna para aprender y reforzar estas ideas y el vocabulario relacionado.

- Preparar los criterios para el éxito: explicar a los alumnos que mientras cuentas la historia ellos tienen que:

- Escuchar atentamente la historia.

- Participar repitiendo palabras y frases con el cuentacuentos.

- Responder a las preguntas que se realicen.

- Intentar adivinar qué va a pasar después.

- Hacerles revisar y reflexionar personalmente:

- ¿Te gustó la historia? ¿Por qué?

- ¿Cómo te sentiste mientras escuchabas la historia?

- ¿Cómo describirías (un personaje, un lugar)?

- ¿Te gustó el final?

- Etc.

- Preparar también actividades post-storytelling: chants, canciones, manualidades, teatro o escenificación, role-play, cuentacuentos de los propios alumnos, representación con marionetas, juegos, echar un vistazo a las ilustraciones desde diferentes perspectivas (buscar detalles, formas, colores, expresiones...), etc. 
- Conseguir el apoyo y la participación de las familias en casa, prolongando el efecto y el valor de la literatura en casa.

También se pueden utilizar recursos digitales para contar cuentos a los alumnos. Las posibilidades son infinitas: desde presentar las imágenes y el texto de un cuentacuentos a través de un proyector, a crear nuestros propios materiales con programas gratuitos y sencillos, pero igualmente motivadores. Aunque existen muchas más, disponibles en la web, las citadas aquí son las más sencillas, económicas y accesibles:

- Open Office Impress - Para presentaciones de diapositivas. Se puede descargar de forma gratuita junto con todo el paquete de Open Office en http://www.openoffice.org/es/.

- Smart Notebook Express - Otro programa que permite realizar una gran variedad de actividades interactivas para pizarra digital. En su web (http://express.smarttech.com/\#) también se pueden descargar actividades interactivas ya elaboradas y modificarlas.

- JCLIC (http://clic.xtec.cat/es/jclic/) y HotPotatoes (http://hotpot.uvic.ca/) Son programas totalmente gratuitos que permiten crear actividades interactivas como puzzles, multiple-choice, crucigramas, juegos de parejas y de ordenación, entre otros. También tienen disponibles para bajar gratuitamente un amplio banco de actividades realizadas por otros usuarios.

Por su parte, Sánchez Terrel en la web de ESOL Technology publica un interesante artículo sobre Digital stories in the ESL classroom ${ }^{2}$. Ella define el digital storytelling no solo como un instrumento de aprendizaje que promueve la escritura correcta, la reflexión y la creatividad, sino también como una "forma artística y una poderosa herramienta para la auto-expresión". Propone que sean los alumnos los que creen sus propias historias digitales, dando vida a una idea concreta a través del uso de imágenes, vídeos, música y narración. En su página web expone los pasos y las técnicas necesarias para que los alumnos puedan diseñar su propia historia digital, así como unos links muy interesantes sobre Digital Storytelling ${ }^{3}$.

Pero además, existe una gran variedad de actividades complementarias a la narración de cuentos que se pueden realizar durante o tras la lectura:

- Cambio de género literario. Por ejemplo, pasar un cuento a obra de teatro o a cómic.

2 Disponible en: http://esoltechnology.com/2009/02/25/digital-stories-in-the-esl-classroom/ [Consulta: 08/03/2015].

${ }^{3}$ Ver: http://shellyterrell.com/survivaltips/digitalstorytelling/ [Consulta: 08/03/2015]. 
- Ordenar una historia cortada en secciones a medida que se va contando, o tras la audición.

- Cambiar una historia conocida por todos, y que la audiencia vaya diciendo qué se está cambiando.

- Investigar sobre un autor o un ilustrador.

- Crear un libro con sus trabajos, que se puede dejar en la biblioteca y servir de inspiración a otros alumnos.

- Y otras muchas, que se pueden encontrar en multitud de libros de recursos especializados para las clases de lengua extranjera (ver más abajo).

\subsection{Obras de teatro}

Las obras de teatro son un complemento ideal para trabajar proyectos que combinen la educación artística con el inglés. El montaje de una obra de teatro, aunque sea breve, preparando no sólo la fonética y la memorización del texto, sino también los disfraces y/o máscaras y las decoraciones del escenario, e incluyendo alguna canción, puede hacer que la obra cobre vida y sea mucho más relevante y más memorable y significativo en el desarrollo de las competencias comunicativas de los alumnos. Si además se relaciona alguna obra con algún aspecto de ciencias -el agua, los animales, la naturaleza, etc.- que se esté impartiendo en ese momento o a lo largo del curso, será una enseñanza más globalizada e interrelacionada que facilitará la comprensión y el aprendizaje de los alumnos.

Por otra parte, el teatro da la oportunidad a los alumnos de responder a las historias de una manera multisensorial y kinestésica, aprendiendo mediante la acción en diferentes niveles de formación (Read, 2007, 115-16). Pero no solamente que los alumnos actúen, sino que también puedan utilizar marionetas de diversas formas, incluso creadas por ellos mismos, para dar vida a una obra de teatro. En un nivel básico, mediante actividades introductorias al teatro, los niños pueden usar mimo, sonido, gestos e imitación para hacer conexiones entre el lenguaje y la expresión corporal. Esto ayuda a los niños pequeños a asociar acciones, palabras y significados y a memorizar y adquirir lenguaje clave de una manera natural y divertida. A un nivel un poco más avanzado, les permite reciclar y utilizar el lenguaje en un contexto, ayudando a construir su confianza a la hora de hablar y pronunciar en inglés, y mejorando por tanto su expresión oral. Si además participan los padres, como colaboradores o como público, estaremos haciendo que la escuela sea un lugar en el que las familias tengan cabida, favoreciendo la motivación y la autoestima de los alumnos.

En Internet se pueden encontrar obras de teatro para niños en inglés gratuitas. Por ejemplo:

- Plays for kids de Lazy Bee Scripts. Es una página en la que se encuentran obras clasificadas por edad, por temas, para actuar en el colegio, para leer (http://www.lazybeescripts.co.uk/youththeatre/). 
- En la sección Resources/Drama Games de la página Beat by Beat Press (http://www.bbbpress.com/dramagames/) se pueden ver distintas ideas para hacer juegos y técnicas de teatro con los niños. Tiene trabalenguas, ejercicios de calentamiento, consejos y distintas actividades para realizar con los niños en clase.

- Drama with Children de la sección Teaching English del British Council da consejos e ideas para utilizar el teatro en inglés: Drama with Children 1 y 2, para auxiliares lingüísticos (http://www.teachingenglish.org.uk/languageassistant/primary-tips/drama-children-1

http://www.teachingenglish.org.uk/language-assistant/primary-tips/dramachildren-2).

- Children's Theatre Scripts and Plays de la página Whootie Owl (http://hazel.forest.net/whootie/script.html). Unas cuantas obras de teatro en inglés, descargables de forma gratuita en pdf. A menudo incluso tiene actividades y cuentos ilustrados relacionados con la obra, también descargables. Aunque en un principio el formato de la página varía mucho y no parece atractivo, lo que ofrece sí lo es.

- Kidsinco ofrece una lista de obras de teatro para niños gratuitas, muchas de ellas basadas en cuentos tradicionales, como por ejemplo Goldilocks and the Three Bears, Sleeping Beauty, The Gingerbread Man o Jack and the Beanstalk. La lista de las obras se puede ver en: http://www.kidsinco.com/complete-list-of-playscripts/.

\subsection{Cómics}

En la red también se pueden encontrar multitud de cómics gratuitos, y muchos se pueden utilizar en el aula:

- The Big Blog of Kids' Comics (http://www.bigblogcomics.com/). Decenas de cómics escaneados de Tom \& Jerry, Elmer Fudd, Woody Woodpecker, Popeye, Little Audrey, Andy Panda, Mr. Magoo, Bugs Bunny, Batty, Dizzy Duck, y un largo etcétera, e incluso versiones de cuentos en cómic, que se pueden ver online, proyectarlos en una pantalla, guardar las imágenes o imprimirlas.

- En GoComics.com (http://www.gocomics.com/explore/comics) se pueden encontrar cientos de cómics de Calvin \& Hobbs, Peanuts, Garfield, Marmaduke, Nancy, Crumb y muchísimos más, normalmente en formato strip (tira cómica: una única línea con tres, cuatro o cinco viñetas solamente). Hay de todas las temáticas, desde con poco texto a mucho.

- En Comics Kingdom también se pueden encontrar cientos de cómics (Zits, Dennis the Menace, Mother Goose \& Grimm, Blondie, Garfield, Popeye, Prince Valiant, Flash Gordon, Mutts, etc.), clasificados por personajes y temática. 
- Aford. The Best Turtle Comic Strip... Ever! Cómic sobre una tortuga llamada Aford T. Turtle y sus amigos, Simon the Snake y Robin, en formato strip. A partir de $4^{\circ}$ curso, en: http://www.riddlesbunnybarn.com/AFORD/.

- Bleeker, the Rechargeable Dog. Otro cómic en strips sobre un perro robot llamado Bleeker. Igualmente a partir de $4^{\circ}$. Disponible en: http://bleekercomics.com/

- Garfield. Página web del famoso gato Garfield, donde se pueden leer muchas de sus tiras cómicas, algunas con muy poco texto, adecuadas para iniciar a los niños en la lectura de cómics (http://garfield.com/).

Muchos de estos cómics pueden utilizarse en clase como skits -pequeñas representaciones teatrales. Así, los alumnos que las memorizan y las representan delante de la clase, practican también la fonética y la memorización de estructuras gramaticales. Sin embargo, utilizando cómics auténticos se pueden realizar otro tipo de actividades:

- Lectura, simplemente por diversión.

- Ordenar las viñetas o los bocadillos de un cómic, para que tenga sentido.

- Análisis del humor, dobles significados de las palabras o frases, que pueden hacer que entiendan mejor tanto el idioma como distintos aspectos socioculturales.

- Creación de sus propios cómics.

Con respecto a este último punto, existen herramientas web gratuitas accesibles a los alumnos. Estas son algunas de ellas:

- Make Beliefs Comix - http://www.makebeliefscomix.com/ - Para crear tiras cómicas de dos, tres y cuatro viñetas en distintos idiomas con las distintas opciones de dibujos, fondos, bocadillos, etc. También se pueden imprimir.

- Comics Head - http://www.comicshead.com/ - Es una app para IOS y Android para hacer cómics, fotocómics, storyboards y presentaciones. Permite añadir tus propias imágenes, además de utilizar su biblioteca de personajes, fondos, etc. La versión Lite - con menos posibilidades- es gratuita.

- Friendstrip - http://www.friendstrip.com/ - Es una app similar a la anterior. Totalmente gratuita.

\subsection{Nursery rhymes y poesía}

Las nursery rhymes son bastante utilizadas en la etapa de Infantil. Son textos literarios populares bastante agradecidos, porque son breves, fáciles de recordar para los niños, a menudo son graciosas y suelen tener unos gestos asociados que las hacen más memorables, más divertidas y más participativas para los alumnos. Además, a su alrededor se pueden trabajar muchas actividades relacionadas, o acoplarlas a 
distintos proyectos que los propios tutores de Infantil estén trabajando en el aula, como por ejemplo, el reloj o los números con Hickory Dickory Dock; la resta con Five Little Monkeys; o los saludos con Hello Thumbkin. Hay multitud de recursos relacionados al respecto, sobre todo libros y páginas web muy interesantes, como por ejemplo la de Mother Goose Club (http://www.mothergooseclub.com/), en la que encontramos vídeos muy atractivos de nursery rhymes tradicionales.

Por otra parte, la poesía es uno de los géneros menos utilizados en la enseñanza del inglés en Primaria. Como mucho se ven chants breves, normalmente relacionados con el trabajo de un fonema determinado. Sin embargo, podemos encontrar materiales poéticos bastante interesantes en páginas web y antologías para niños:

- Giggle Poetry (http://www.gigglepoetry.com/). Tiene poemas muy divertidos, incluyendo poemas cortos que se pueden representar o leer por varios niños en clase y actividades para trabajar la creación de poemas literarios en clase.

- Poetry for Kids (http://www.poetry4kids.com/poems), la página web del escritor Kenn Nesbitt en la que hay divertidos poemas para niños. Un ejemplo de los títulos: My Pig Won't Let Me Watch TV; Today I Had a Rotten Day; I Taught My Cat to Clean My Room, entre otros. En esta misma página encontramos juegos poéticos online (Poetry Fun and Games: http://www.poetry4kids.com/games), lecciones de poesía para niños (http://www.poetry4kids.com/blog/lessons/poetry-writing-lessons/) y grabaciones del propio autor leyendo algunos de sus poemas (podcasts: http://www.poetry4kids.com/blog/category/podcast/).

- Poems for Children - The Classics. Muy buena selección de poemas para niños de autores consagrados de la literatura en lengua inglesa, como Robert Louis Stevenson, Lewis Carrol, Edward Lear, Robert Frost, Mary Hewitt, Sarah Coleridge, Christina Rosetti, etc. (http://www.storyit.com/Classics/ JustPoems/).

- Children's Poetry Archive. Selección de poemas de autores actuales, en el que también se pueden encontrar grabaciones de los poemas leídos y entrevistas con sus autores. Ofrece una búsqueda por temática, formato del poema o autor (http://www.poetryarchive.org/childrensarchive/home.do).

Los poemas pueden servir de modelo y pueden ayudar a los alumnos a reutilizar el lenguaje aprendido y a expresarse en inglés de una manera nueva y creativa. En esta línea, Holmes y Moulton (2001) en su libro Writing Simple Poems proponen una amplia lista de patrones con ejemplos y pautas para el profesor de tal forma que los alumnos tengan una guía sencilla para elaborar sus propios poemas. Así, encontramos estructuras y ejemplos para realizar acrósticos, poemas alfabéticos, biopoemas, poemas de cinco sentidos, poemas sobre "I am", "I like" o "I wish", poemas con los 
días de la semana, con metáforas de color e incluso haikus ${ }^{4}$, por citar algunos. Además, se puede hacer un mural en clase o una exposición en la escuela con todos los poemas, o incluirlos en el blog de la clase, o incluso recopilarlos en un libro que esté a disposición de los lectores de la biblioteca escolar en cursos sucesivos. A los alumnos les resultará interesante, motivador e incluso halagador, que sus obras literarias compartan estantería con algunos de sus libros favoritos.

\subsection{La biblioteca escolar}

La biblioteca del centro y sus responsables desarrollan un papel muy importante tanto en la dinamización del centro como en la promoción de la literatura en general en el centro escolar. Cada biblioteca debería tener un fondo variado de libros en distintas lenguas, a ser posible una gran parte de ellos prestables. Mallet (2010: 1213) afirma que a la hora de seleccionar recursos para la clase y la biblioteca escolar hay que tener en cuenta determinados materiales:

- Libros que han llegado a ser clásicos atemporales así como libros y autores actuales.

- Libros en préstamo de la librería pública local, así como una colección permanente.

- Libros hechos por profesores y alumnos (encuadernados y plastificados, para que duren).

- Textos multimedia, incluyendo CD de audio, DVD, CD-Rom, audiolibros y películas sobre historias.

- Textos populares que ofrezcan un vínculo entre la lectura en el colegio y el hogar del alumno.

- Libros y recursos con diferentes niveles de dificultad, para cubrir las necesidades de todos los alumnos.

- Libros bilingües.

- Libros de temática local o regional.

- Textos de calidad de diferentes partes del mundo, así como cuentos tradicionales para reforzar nuestro patrimonio cultural común.

Asimismo, sería interesante que la biblioteca del colegio fomentara también el uso de estos recursos, y que, por un lado, se programaran actividades en distintas lenguas, y por otro, se incluyeran libros e historias de diversos idiomas en las demás actividades generales del centro, como el Día del Libro o las distintas fiestas y/o efemérides que se festejen, como nacimientos de autores, cumpleaños de primeras

${ }^{4}$ Composición poética de origen japonés que consta de tres versos de cinco, siete y cinco sílabas respectivamente. Disponible en: http://dle.rae.es/?id=JyK0w1N [Consulta: 23/09/ 2016] 
ediciones de libros, etc. Son formas de dar a conocer los fondos que tiene la biblioteca y animar a su préstamo y lectura.

Williams (2013) hace una serie de propuestas para fomentar la lectura por placer -en cualquier lengua - en la escuela, que implica a las actividades realizadas en la biblioteca, como por ejemplo, proporcionar libros con textos de literatura auténtica que sean atractivos; crear una zona de lectura en el aula que sea agradable; poner a disposición de los niños en la biblioteca no solo libros, sino también DVD, TIC, marionetas, objetos que pueden cobrar vida, música, etc.; tener invitados en la biblioteca escolar para leer, hablar y entusiasmarles hacia la literatura (escritores, cuentacuentos, abuelos, madres y padres); crear una Cultura Lectora en el colegio.

A esto se pueden añadir también algunas otras ideas, por ejemplo, crear una biblioteca de aula a partir de los préstamos de la propia biblioteca del centro, o de las bibliotecas públicas locales o regionales, cuyos libros pueden ser cambiados según se cambien los centros de interés, los proyectos del aula, a petición de los alumnos (si se considera adecuado), etc. Otra idea es el Bibliopatio, que pone a disposición de los alumnos un carro de biblioteca que se saca en los recreos para aquellos que quieran leer en esos periodos.

Para poder realizar todo esto es necesario que toda la Comunidad Educativa (alumnos, familias, educadores, personal no docente del centro) participe de la Cultura Lectora que se comentaba más arriba.

\subsection{El portfolio literario del profesor}

Según un reciente estudio de Cremin et al. (2008, citado por Waugh et al., 2013), muchos profesores no conocen la literatura infantil actual y/o no tienen ningún interés en ella. Cremin et al. (2008) indican que el escaso abanico de lecturas ofrecidas por los profesores hace que muchos niños no se encuentren atraídos por la literatura en la escuela. Si a esto le sumamos las dificultades que puedan encontrar en sus hogares para acceder a la lectura (problemas económicos, dificultades de acceso a libros variados, bajo nivel sociocultural de las familias), observamos que muchos niños no encuentran ningún aliciente a la hora de leer.

En este sentido, Waugh et al. (2013) proponen que los profesores creen su propio portfolio literario. Los pasos para crearlo serían los siguientes:

1. Buscar tablas de los libros infantiles más vendidos actualmente y de los libros infantiles más leídos a lo largo de un tiempo determinado (por ejemplo, en los últimos treinta años). Esto se puede encontrar en muchas páginas web, como por ejemplo en http://www.riverfallspubliclibrary.org/readers/ child.htm, una tabla con los libros más vendidos en EE.UU en 2013 -picture books, children's middle grade, young adult-; http://www.nypl.org/ childrens100, una lista de la Biblioteca Pública de Nueva York con los libros infantiles más leídos votados por sus usuarios (descargable también en .pdf). 
Hay otras páginas web relacionadas que se listan en la sección Recursos adicionales.

2. Identificar aquellos libros que el profesor ha leído y hacer breves comentarios sobre ellos, anotando principalmente:

- Edades que podrían disfrutar este libro.

- Con qué temas de otras materias se puede relacionar.

- Qué tipo de actividades se podrían realizar con él que sean atractivas (lectura en gran grupo, lectura individual, cuentacuentos, representaciones, otro tipo de actividades).

- Qué otros libros podrían gustarle a aquellos a los que disfruten con este libro.

3. Igualmente, anotar estos mismos comentarios a medida que vamos leyendo otros libros de la lista, u otros distintos que vayamos añadiendo.

Este portfolio ayudará a los profesores a tener en cuenta su propio material y a ampliar su conocimiento sobre la literatura de una manera eficaz, de tal manera que tengan un amplio repertorio y recursos para encontrar la literatura adecuada para usar en clase en cada momento. Además, puede ser realizado a nivel personal por un solo profesor o como anexo al plan lector del centro, realizado por un grupo o por el claustro de profesores completo. Se puede incluso contar con la colaboración de otros sectores de la Comunidad Educativa (recomendaciones del personal no docente, familias, incluso alumnos), como una ayuda para el desarrollo de la Cultura Lectora del centro.

\subsection{Recursos adicionales. Páginas web y libros recomendados}

Para profundizar en el uso y la investigación sobre la literatura infantil en general, y sobre la literatura en inglés en particular, Bland y Lütge (2013, 223-224) recomiendan las siguientes páginas web:

- Organizaciones:

- The Children's Literature Assembly (www.childrensliterature.org). Una organización dedicada a unir a los defensores de la literatura infantil como una literatura valiosa, importante, de calidad y necesaria para la sociedad.

- Children's Literature Association (www.childlitassn.org). Una asociación sin ánimo de lucro que incluye a investigadores, críticos, profesores, estudiantes, bibliotecarios e instituciones dedicadas al estudio académico de la literatura.

- International Research Society for Children's Literature (www.iscrl.com). Una asociación internacional de investigadores fundada para respaldar y promover la investigación en el campo de la literatura infantil. 
- Society of Children's Book Writers and Illustrators (www.scbwi.org). Una organización para escritores e ilustradores -tanto nuevos como experimentados- que trabajen en literatura infantil.

- Publicaciones periódicas:

- La nueva revista online Children's Literature in English Language Education, disponible en http://clelejournal.org/, cuyo primer número apareció en mayo de 2013, se propone aportar de manera anual ideas, materiales y técnicas referidas a cuentos y libros concretos, para distintos niveles.

- Children's Literature Association Quarterly (http://muse.jhu.edu/journals/ childrens_literature_association_quarterly/). Cada número presenta una introducción, artículos de investigación evaluados por expertos y críticas de libros.

- Children's Literature in Education. An International Quarterly (www.springer.com/education+\&26language/linguistics/journal/10583). Esta revista ha sido durante casi 40 años una fuente de artículos clave en todos los aspectos acerca de la literatura para niños.

- The Journal of Children's Literature Studies (www.piedpiper publishing.com/journals.org). Esta revista cuatrimestral incluye investigaciones sobre todos los aspectos de la literatura infantil, la infancia y los libros para niños.

Para conocer el mercado editorial y poder escoger libros en inglés interesantes, también se recomienda visitar las siguientes páginas web:

- Picturebooks in ELT. Blog dedicado a la presentación y crítica de cuentos cortos actuales para niños nativos, (http://picturebooksinelt. blogspot.com.es/2012/05/book-of-phobias.html) pero enfocado desde el punto de vista de su utilización en la clase de inglés como lengua extranjera literatura auténtica.

- Children's Book Council es una fundación sin ánimo de lucro creada por distintos editores de libros en lengua inglesa para promocionar la lectura, en colaboración con la International Reading Association. En su página se pueden encontrar también las novedades editoriales y recomendaciones de libros. Es interesante el apartado Reading Lists (en la sección Find Books: http://www.cbcbooks.org/reading-lists/), donde se pueden encontrar listas de libros interesantes, hechas anualmente desde 1974 por profesores, los propios niños y especialistas en literatura infantil para diferentes situaciones: leer en casa, crear tu propia biblioteca, libros de referencia, libros para leer en vacaciones, etc.

- Sweet on Books (http://sweetonbooks.com). Página web en la que se hace un análisis de las novedades editoriales. Tiene buscador para poder ver libros por 
nivel de lectura, título, autor, categoría y puntuación. También tiene entrevistas con autores.

- Books for Keeps. Revista británica online gratuita sobre literatura infantil (http://booksforkeeps.co.uk). Cientos de libros son analizados cada año. Quien lo desee se puede suscribir a su newsletter, donde informan de las novedades y de cuándo sale el último número, que se puede ver online o descargarlo.

- The Teachers' Lounge (http://blog.reallygoodstuff.com/). Blog con multitud de ideas para utilizar en clase, realizado con las aportaciones de diferentes profesores. La sección Classroom Library (a la que se llega pinchando en Classroom Ideas primero) da muchos consejos para la mejora de la biblioteca escolar: libros, organización, animación a la lectura, etc. En la sección de Lesson Plans \& Ideas se pueden encontrar actividades para la utilización de la literatura en el aula -entre otras- clasificadas por edades. Aunque está ligada a una tienda online, las ideas y consejos son bastante relevantes y pueden servir de inspiración para la variedad de contextos en las aulas.

- School Library Journal (www.slj.com/\#) es una página en la que también se revisan las novedades literarias del mes, y se recomiendan diferentes libros en inglés para bibliotecas escolares. Ideal para mantenerse actualizado del mercado editorial. Es interesante también su blog sobre cómics para niños y adolescentes (http://blogs.slj.com/goodcomicsforkids/).

- The Society for Storytelling (www.sfs.org.uk) es una asociación, fundada en 1993, para promover el antiguo arte de contar historias oralmente. En su sección de Resources se pueden descargar una serie de artículos llenos de ideas sobre contar cuentos y crear eventos alrededor de la literatura, tanto para las familias como para bibliotecas, museos, librerías u otras organizaciones.

- Love Reading for Kids (www.lovereading4kids.co.uk) es una página web que también publica listas de libros más vendidos, recomendaciones por edades y repaso de las últimas novedades y los autores más actuales.

Aparte de los libros citados a lo largo de esta sección, existe una extensa bibliografía sobre los distintos temas tratados, como por ejemplo:

- Storytelling:

- Medlicott, M. (2010). Stories for Young Children and How to Tell Them! Leicestershire: Featherstone Education. Una colección de historias y consejos para contarlas. Con audio CD.

- Trelease, J. (2013). The Read-Aloud Handbook (7th edition). New York: Penguin. Reflexiones, consejos y recomendaciones sobre cómo acercar la lectura a los niños.

- Wright, Andrew (2008). Storytelling with children. Oxford: OUP. Una amplia variedad de actividades para trabajar los cuentos en el aula de inglés. 
-Zipes, J. (1995). Creative storytelling. NewYork: Routledge. Recomendaciones y cuentos para contar y crear en la escuela.

- Ellis, G. \& Brewster, J. (2014). Tell it again! The New Storytelling Handbook for Primary Teachers. London: Pearson ELT. Reedición renovada y revisada del antiguo libro de Ellis y Brewster de 1991. Con muchas fichas fotocopiables y recomendaciones. Disponible en: http://www.teachingenglish.org.uk/sites/ teacheng/files/D467_Storytelling_handbook_FINAL_web.pdf

- Nursery Rhymes:

- Gliori, D. (2005). Nursery Rhymes. London: DK Publishers Ltd. Ilustradas a color, con CD para escuchar y algunas pistas sobre el origen o el uso de cada rima.

- Graham, Carolyn (1994). Mother Goose Jazz Chants. Oxford: OUP. Nursery rhymes y canciones tradicionales en el estilo de Carolyn Graham, ilustradas a color, y que se pueden escuchar y hacer que los niños aprendan fácilmente.

- Baxter, N. (2012). Classic Nursery Rhymes. San Francisco: Armadillo Books. Una colección de cien nursery rhymes, ilustrado en estilo antiguo a color.

- Otros libros:

- Graham, Carolyn (1998). Jazz Chants Fairy Tales. Oxford: OUP. Este libro es muy interesante, porque es una colección de ocho conocidos cuentos tradicionales (Goldilocks and the Three Bears, The Three Billy Goats Gruff, Little Red Riding Hood, etc.) adaptados a la forma del Jazz Chant de Graham y de teatro, lo que da la posibilidad de que además los alumnos los puedan escenificar.

- Mallet, M. (2010). Choosing and Using Fiction and Non-Fiction 3-11. New York: Routledge. Un libro-guía sobre cómo escoger y usar libros para niños. Aunque es para niños nativos, se pueden sacar muchas ideas y recursos.

- Read, C. (2007). 500 Activities for the Primary Classroom. London: Macmillan. Tiene un apartado sobre drama y storytelling con actividades muy interesantes. Además, tiene un montón de recursos más para trabajar muchos más temas y aspectos del lenguaje.

- Roth, G. (2002). Teaching Very Young Children. London: Richmond Publishing. Un libro muy interesante con muchas ideas y fichas fotocopiables para los profesores de inglés de niños a partir de 3-4 años.

- Taylor, E. K. (2000). Using Folktales. Cambridge: CUP. Cuentos tradicionales de diferentes partes del mundo, con actividades relacionadas, para distintos niveles y edades.

Por último, hay gran variedad de webinars sobre la literatura en las aulas de Infantil y Primaria, pero hay que resaltar las que se grabaron en la Story Sharing Web 
Conference de 2013 en Turquía (http://www.teachingenglish.org.uk/turkey), entre las que se pueden destacar estas dos como ejemplo:

- Alec Williams: Reading for Pleasure: Why it Matters, How it Helps and Ways to Enjoy it. https://britishcouncil.adobeconnect.com/_a917587435/ p4eucnrboig

- Gail Ellis: Using Story Picturebooks with Primary School Children http://britishcouncil.adobeconnect.com/p7ujx1u7wkn/

\section{CONCLUSIÓN}

La literatura es un recurso muy interesante y versátil para el aprendizaje de lenguas, ya que proporciona un contexto adecuado para adquirir nuevas estructuras y vocabulario, y para que el alumno pueda usarlo, facilitando su aprendizaje. El uso de textos literarios puede complementar cualquier metodología, dando además una motivación extra que solamente ella, quizá junto a las canciones y a las películas, puede aportar. Además, con la ayuda de las nuevas tecnologías, la literatura en las aulas de inglés puede resultar muy motivadora, y puede favorecer la participación en nuevas experiencias agradables y enriquecedoras para nuestros alumnos, ampliando sus horizontes y favoreciendo el desarrollo de la tolerancia y el respeto a distintas culturas.

\section{BIBLIOGRAFÍA}

BAXTER, Nicola (2012): Classic nursery rhymes, San Francisco, Armadillo Books.

BLAND, Janice \& LÜTGE, Christiane (eds.) (2013): Children's literature in second language education, London, Bloomsbury.

BRITISH COUNCIL (2006): Orientaciones para el desarrollo del currículo integrado hispano-británico. Convenio MEC - British Council, Madrid, MEC.

ELLIS, Gail \& BREWSTER, Jean (1991): The storytelling handbook for primary teachers, London, Penguin English.

ELLIS, Gail \& BREWSTER, Jean (2014): Tell it again! The new storytelling handbook for primary teachers, London, Pearson ELT. Disponible en Web: http://www.teachingenglish.org.uk/sites/teacheng/files/D467_Storytelling_handb ook_FINAL_web.pdf [Consulta: 08/03/2015].

ELLIS, Gail (2013): Using story picturebooks with primary school children (conference) - Story Sharing Web Conference (Turkey, 9/2/2013). http://britishcouncil.adobeconnect.com/p7ujx 1u 7wkn/ [Consulta: 08/03/2015].

GLIORI, Debi (2005): Nursery rhymes, London, DK Publishers Ltd.

GRAHAM, Carolyn (1998): Jazz chants fairy tales, Oxford, OUP.

GRAHAM, Carolyn (1994): Mother Goose jazz chants, Oxford, OUP.

Holmes, Vicki L. \& Moulton, Margaret R. (2001): Writing simple poems. Pattern poetry for language acquisition, Cambridge, CUP. 
MALLET, Margaret (2010): Choosing and using fiction and non-fiction 3-11, New York, Routledge.

MedLicotT, Mary (2010): Stories for young children and how to tell them!, Leicestershire, Featherstone Education.

READ, Carol (2007): 500 Activities for the primary classroom, London, Macmillan.

RотH, Genevieve (2002): Teaching very young children, London, Richmond Publishing.

TAYLOR, Eric K. (2000): Using folktales, Cambridge, CUP.

TOMLINSON, B. (1994). Openings. Language through literature. An activities book, London, Penguin.

TRELEASE, Jim (2013): The read-aloud handbook. $7^{\text {th }}$ edition, New York, Penguin Books.

Waugh, D., Neaum, S. \& Waugh, R. (2013): Children's literature in primary schools, London, Learning Matters. Kindle Edition.

WILLIAMS, Alec (2013): Reading for pleasure: Why it matters, how it helps and ways to enjoy it. Webinar in Story Sharing Web Conference, British Council Turkey 2013. https://britishcouncil.adobeconnect.com/_a917587435/p4eucnrboig [Consulta: 08/ 03/2015].

WRIGHT, Andrew (2008): Storytelling with children, Oxford, OUP. 